\title{
Optimal selection of operating parameters in end milling of Al-6061 work materials using multi-objective approach
}

\author{
Jakeer Hussain Shaik ${ }^{*}$ and Srinivas J
}

\begin{abstract}
Background: Machining using vertical CNC end mill is popular in the modern material removal industries because of its ability to remove the material at a fast rate with a reasonably good surface quality.

Methods: In this work, the influence of important common machining process variables like feed, cutting speed and axial depth of cut on the output parameters such as surface roughness and amplitude of tool vibration levels in Al-6061 workpieces has been studied. With the use of experimental result analysis and mathematical modelling, correlations between the cutting process conditions and process outputs are studied in detail. The cutting experiments are planned with response surface methodology (RSM) using Box-Behnken design (BBD).
\end{abstract}

Results: This work proposes a multi-objective optimization approach based on genetic algorithms using experimental data so as to simultaneously minimize the tool vibration amplitudes and work-piece surface roughness. The optimum combination of process variable is further verified by the radial basis neural network model.

Conclusions: Finally, based on the multi-objective optimization approach and neural network models an interactive platform is developed to obtain the correct combination of process parameters.

Keywords: Al-6061 work-piece, Box-Behnken design, Multi-objective optimization, Neural network, Surface roughness, Tool vibration amplitudes

\section{Background}

For the metal-working industry, a continuous reduction in manufacturing cost is desirable. An important issue related to reduce overall cost consists of the removal of undesirable or excess work piece material during the machining process. Among different types of material removal operations, end-milling is most important common milling operation due to its capability of producing complex geometric surfaces with reasonable accuracy and surface finish. Over the last two decades, several works focused on the optimum selection of machining parameters based on various criteria such as using basic mathematical models. Some contemporary literature is first presented. Brito et al. (2014) developed a robust parameter design for the process parameters using the

\footnotetext{
* Correspondence: jakeershaik786@yahoo.co.in

Department of Mechanical Engineering, National Institute of Technology Rourkela, Rourkela, Odisha 769008, India
}

multi-objective methods. The numerical results are validated with the experimental cutting tests. Mathivanan et al. (2016) studied the influence of cutting parameters on milling of the composite materials. A CNC end milling was used to machine the composite laminates at various combinations of speeds and depth of cuts. Numan durakbasa et al. (2015) presented the various end milling process parameters as well as the coatings on the surface quality of the machined parts of AISI H13 hot work steel. Some researchers (eg., Hocheng et al. (1997), Arokiadass (2012) and Surinder (2015)) investigated the machining characteristics of an aluminium based composite alloy for the end-milling process. Experiments were conducted based on the central composite design and Analysis of Variance (ANOVA) was used to build the mathematical model. Zhang et al. (2016) implemented a systematic optimization approach to obtain the pareto-optimal values of cutting process 
parameters. Dikshit et al. (2014a, 2014b) studied the cutting process parameters in dry machining of aluminium alloys. Response surface methodology was planned to carry out the experiments and further genetic algorithms were implemented to obtain the optimal parameters such as the cutting speed, feed per tooth, axial and radial depth of cut. Karkalos et al. (2016) focused on the machining of Titanium alloy with the peripheral down milling process and further optimal control studies were implemented to minimize the surface roughness. Ratnam et al. (2016) studied the turn-milling process in tangential and orthogonal directions to minimize the surface roughness of extruded brass material. Several recent works focussed on the optimal machining parameters for multi-pass milling operations by considering the statistical and artificial intelligent techniques (Wang et al. 2005; Sukumar et al. 2014; Venkata Rao and Pawar 2010; Das et al. 2016; Ren et al. 2016). The efficiency of a neural network model was estimated by conducting the numerical simulations and experiments. Several studies had been focussed on the optimization of important cutting process parameters using intelligent optimization techniques like genetic algorithms and radial basis neural networks (Briceno et al. 2002; Mounayri et al. 2010; Mounayri et al. 2005). Using, different neural network models and optimization algorithms the impact of the surface roughness on the process parameters are extensively studied (Palanisamy et al. 2007; Palanisamy and Kalidass 2014; Zain et al. 2011; Saffar and Razfar 2010). Khorasani et al. (2016) studied the effects of cutting parameters and cutting fluid pressure intensity on the surface roughness of milled parts. The important parameters were modelled and analysed using both the multi-layer perceptron and radial basis neural networks.

In spite of above works, very few works are found in literature dealing with the optimal process parameter selection based on simultaneously minimization of tool vibration amplitudes during cutting as well as surface roughness average values of the workpiece. The milling experiments are conducted on the $\mathrm{CNC}$ vertical milling machining centre by considering three levels of feed rate, spindle speed and axial depth of cut. Using the response surface methodology with Box-Behnken design, a mathematical model is developed to predict the surface roughness and amplitude of tool vibration levels in terms of the cutting process variables. Using the experimental data, neural network model is created to approximate the relationship between the three process parameters and two output variables. Furthermore, the equations obtained from response surface methodology are employed as function-estimators for GA-based optimization module, which attempts to minimize simultaneously the tool vibration amplitude and average roughness. The resulting optimum process parameters are reported and discussions are made. Thus, data generation, interaction of responses, implementation of multi-objective genetic algorithms, parallel radial basis neural network modelling for comparison of results is explained one after the other.

\section{Methods}

Experimental work is conducted on a CNC milling center (MAXMILL-make MTAB) employing user defined spindle speeds, depth of cut and feed motions. A $12 \mathrm{~mm}$ diameter HSS tool with four cutting flutes with $50 \mathrm{~mm}$ overhang and a spindle speed of $4000 \mathrm{rpm}$ is employed through-out all the experiments. End milling operations are carried out with full percentage of radial immersion is conducted on the Al6061 work pieces. The chemical composition of this alloy is: $0.3 \% \mathrm{Cu}, 0.04 \% \mathrm{Mn}$, $0.85 \% \mathrm{Mg}, 0.04 \% \mathrm{Ti}, 0.5 \% \mathrm{Si}, 0.2 \% \mathrm{Cr}, 0.5 \% \mathrm{Fe}, 0.25 \%$ $\mathrm{Zn}$, and rest is aluminium. All the specimens were taken in the form of blocks of sizes $100 \times 80 \times 10 \mathrm{~mm}$. At the specified spindle speeds and depth of cut, the vibration amplitudes are recorded by the following instruments: an accelerometer (PG $109 \mathrm{M} 0$, frequency range 1 to 10,000 Hz), a 4-channel digital oscilloscope (model-DPO 43034) with charge amplifier (Model: CA 201 A0). The accelerometer is placed at the housing of the spindle and the corresponding data are recorded in the oscilloscope. Figure 1 shows the experimental set-up employed in present work on the machining center.

In order to assess the quality of the product, surface roughness is an important measure. It greatly influences the performance of mechanical parts as well as production cost. Proper selection of cutting parameters produces a good surface finish. The roughness of the machined surfaces was examined by the Talysurf instrument as shown in the Fig. 2.

Box-Behnken design (BBD) of response surface methodology (RSM) is used to get the fifteen sets experiments with a mathematical model. This method generally requires fewer experiments compared to the rotational central composite design (RCCD) of RSM. The three machining parameters are selected to study the feed $(\mathrm{mm} / \mathrm{min})$, speed ( $\mathrm{rpm}$ ) and axial depth of cut (b). These three machining parameters are selected based on the preliminary trial tests. Table 1 shows the machining parameters and their levels.

It is generally, sufficient to fit a quadratic model and contains the linear terms, squared terms and products of factors. Table 2 shows the experimental outcomes of the input response parameters.

\section{Response surface modeling}

The RSM is a collection of statistical and mathematical methods for the modeling and optimization of the engineering science problems. These method is utilized 


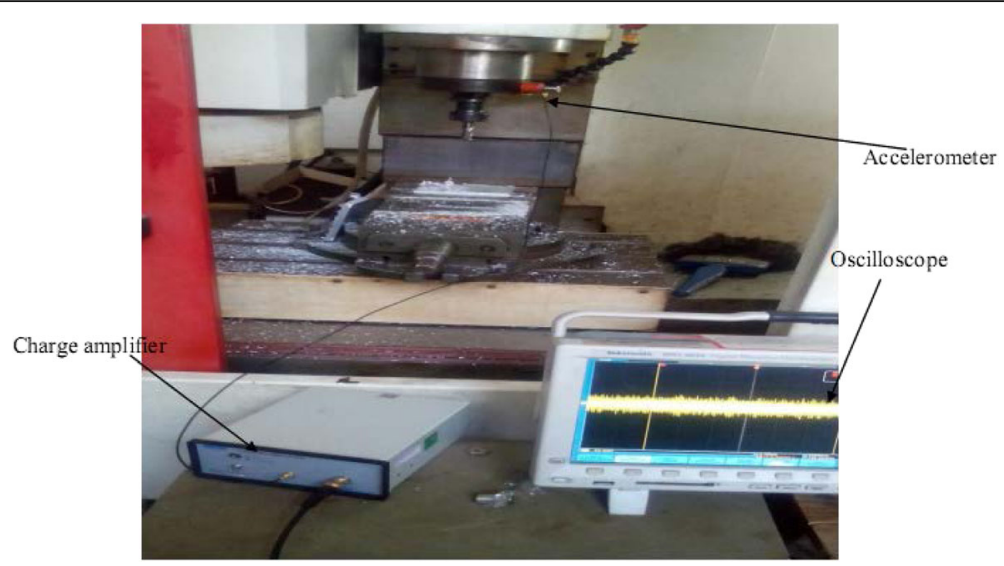

Fig. 1 Experimental set-up employed for in-situ vibration measurements

to develop a relation between input parameters and performance characteristics. During modeling of manufacturing processes using RSM, sufficient data is collected through design of experiment. In general, a second-order regression model is mostly developed because first-order models often give some lack-of-fit. All the input process parameters are assumed to be measurable quantity during modeling and the corresponding responses can be expressed as follows:

$$
y=f\left(x_{1}, x_{2}, \ldots \ldots, x_{p}\right)
$$

where $\mathrm{x}_{1}, x_{2}, \mathrm{x}_{3}, \ldots, \mathrm{x}_{\mathrm{p}}$ are input process parameters and $y$ is response. During experimentation, it is assumed that all the input parameters are controllable and have negligible errors. It is also required to find a suitable approximation between input variables and responses. The second-order RSM model used for modeling of the experimental data is given below:

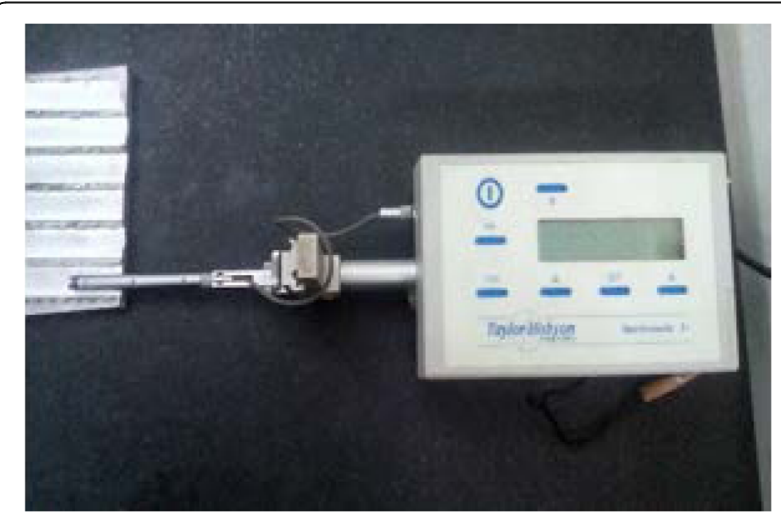

Fig. 2 Talysurf instrument for surface roughness used

$$
y=b_{0}+\sum_{i=1}^{k} b_{i} x_{i}+\sum_{i=1}^{k} b_{i i} x_{i}^{2}+\sum_{i} \sum_{j} b_{i j} x_{i} x_{j}
$$

where $b_{0}$ is constant and $b_{i} b_{i i}, b_{i j} \ldots . .$. , are regression coefficients determined by least squares method. The second-order mathematical model for amplitude of tool vibration level (A) and surface roughness $\left(R_{a}\right)$ has been developed from the experimental data using Minitab software. The second order mathematical model for predicting the $\mathrm{A}$ and $\mathrm{Ra}$ are given as:

$$
\begin{aligned}
& \text { Amplitude }(A)=(-0.064416-0.002188 \times f \\
& +0.000296 \times N-0.556870 \times b \\
& +0.000127 \times f^{2}+0.476204 \times b^{2} \\
& -0.000002 \times f \times N-0.007042 \times f \\
& \times b+0.000124 \times N \times b)
\end{aligned}
$$

$$
\text { Surface roughness } \begin{aligned}
\left(R_{a}\right) & =(-4.31386-0.00399 \times f \\
& +0.00554 \times N-4.83889 \times b \\
& +0.00004 \times f^{2}-0.95278 \times b^{2} \\
& -0.00003 \times f \times N+0.07750 \\
& \times f \times b+0.00083 \times N \times b)
\end{aligned}
$$

The coefficients in the above expressions signifies the weightage factorial values on the output responses. The positive and negative signs of the coefficients reflect the respective proportionality.

Table 1 Machining parameters and their levels

\begin{tabular}{llll}
\hline S. No & Factor & Low & High \\
\hline 1 & Spindle speed $(\mathrm{rpm})$ & 1800 & 3000 \\
2 & Feed rate $(\mathrm{mm} / \mathrm{min})$ & 20 & 60 \\
3 & Axial depth of cut $(\mathrm{mm})$ & 0.2 & 0.8 \\
\hline
\end{tabular}


Table 2 Experimental layout for the BBD

\begin{tabular}{lllccc}
\hline $\begin{array}{l}\text { Std } \\
\text { Order }\end{array}$ & $\begin{array}{l}\text { Feed(f) } \\
(\mathrm{mm} / \mathrm{min})\end{array}$ & $\begin{array}{l}\text { Speed(s) } \\
(\mathrm{rpm})\end{array}$ & $\begin{array}{l}\text { Axial depth of } \\
\text { cut(b)(mm) }\end{array}$ & $\begin{array}{l}\text { Amplitude of } \\
\text { vibration } \\
\text { level(A)(mv) }\end{array}$ & $\begin{array}{l}\text { Surface } \\
\text { roughness } \\
(\text { Ra) } \mu \mathrm{m}\end{array}$ \\
\hline 1 & 20 & 1800 & 0.5 & 0.0640 & 0.800 \\
2 & 60 & 1800 & 0.5 & 0.1430 & 0.333 \\
3 & 20 & 3000 & 0.5 & 0.1128 & 2.200 \\
4 & 60 & 3000 & 0.5 & 0.0944 & 0.333 \\
5 & 20 & 2400 & 0.2 & 0.1780 & 2.860 \\
6 & 60 & 2400 & 0.2 & 0.1980 & 0.530 \\
7 & 20 & 2400 & 0.8 & 0.2220 & 0.800 \\
8 & 60 & 2400 & 0.8 & 0.0730 & 0.330 \\
9 & 40 & 1800 & 0.2 & 0.1462 & 0.200 \\
10 & 40 & 3000 & 0.2 & 0.0834 & 1.130 \\
11 & 40 & 1800 & 0.8 & 0.0634 & 0.200 \\
12 & 40 & 3000 & 0.8 & 0.0896 & 1.730 \\
13 & 40 & 2400 & 0.5 & 0.0752 & 1.200 \\
14 & 40 & 2400 & 0.5 & 0.0752 & 1.200 \\
15 & 40 & 2400 & 0.5 & 0.0720 & 1.200 \\
\hline & & & & & \\
\hline
\end{tabular}

\section{Multi-objective optimization}

In order to obtain the optimal solutions for different design problems with various input data sets optimization methods are needed severely. In single optimization problem, there is only one output criterion and such work has been studied over the past 50 years. When there is more than one objective, a different treatment is required. The multi-objective problems ascend in the complex real world industries like machining, design, transportation industries etc. It is seen that, all the important real world practical problems involving multiple criteria with several constraints are drawing much attention towards the multi-objective optimization. These problems could be effectively solved with less computational effort and high accuracy. In multi-objective optimization problems, genetic algorithms approach is a better technique compared to other methods and has received considerable attention by the researchers. GA is based on the principle of survival for the fittest. In this method, initially a population of strings is selected randomly. These are encoded in binary digits and it is traditionally used to signify the chromosomes using with zeros and ones. Further, the fitness value (maximization or minimization problems) is computed. Further to create a new population, operations like reproduction, crossover and mutation were applied consecutively. Once the new population is generated it is further evaluated and tested for the conformability.

The aim of this study is to minimize the amplitude of vibrations and at the same time minimize the surface roughness $\left(R_{a}\right)$. Here, the response parameters (A and $R_{a}$ ) are non-linear functions of feed rate (f), spindle speed $(\mathrm{N})$, and axial depth of cut (b). The objective function is defined as follows:

$$
\begin{aligned}
& \text { Minimize }\{f(X), g(X)\} \\
& \text { Subjected to variable bounds } \\
& 1800 \leq N \leq 3000 \\
& 20 \leq f \leq 60 \\
& 0.2 \leq b \leq 0.8
\end{aligned}
$$

With $X=[N, f, b]^{\mathrm{T}}$ and $\mathrm{N}, f$ and $b$ represent the speed, feed and axial depth of cut. The function of $f(X)$ and $g(X)$ represents the amplitude of vibration and surface roughness, which are unknown and to be fitted from the experimental data.

Once all the genetic algorithm operators are applied successfully, it will produce a new set of population. Further they are decoded and the corresponding objective function values were calculated. All these operations would complete one generation of genetic algorithm. The iterations will be further continued till the required termination condition is obtained. The flow of genetic algorithm concepts is shown in Fig. 3.

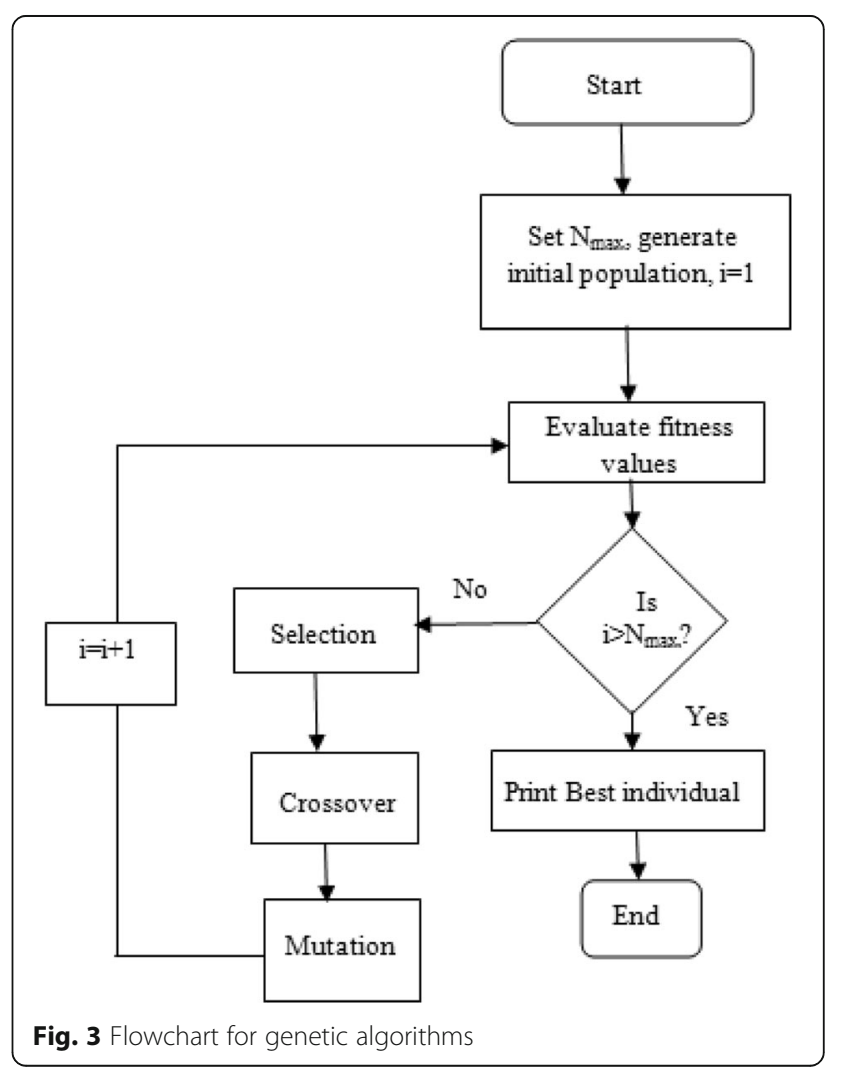




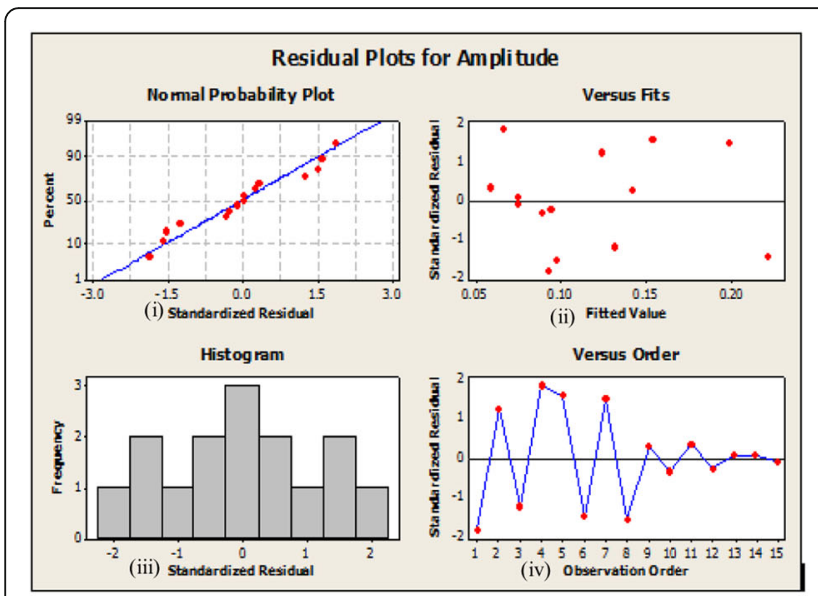

(a)

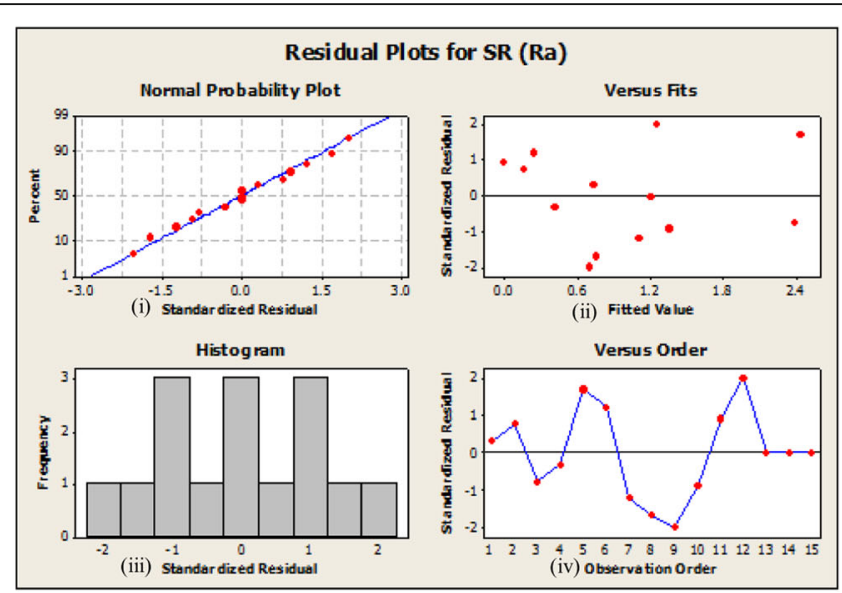

(b)

Fig. 4 Residual plots for the response. a Normality testing for amplitude. b Normality testing for surface roughness

\section{Results and discussions}

All the analysis of the data samples are performed by using the Minitab software. Initially the data of the input and output factors were checked for normality using the probability plots as shown in the Fig. 4. It is observed from the normal probability plots of the amplitude and surface roughness, all the data points are distributed along the normal line which confirms that all the points are normally distributed. The second plot of both the outputs reveals that the all the data points are not followed any particular trend which clearly suggests that this design is well fitted with the given data set and it is varied between the limits between the -2 to 2 . The third plots of the response shows the frequency histogram of data distribution. The fourth plot of the responses shows the residue versus the observation data points highlights the random points which signifies non-significance of experimental order as far as the responses are concerned.

Figure 5 illustrates the main effect plot for means of amplitude of vibration level and surface roughness for the level of process parameters. Main effects plots are drawn to relate several factors at same time and display the response means for each factor level in a sorted order. It graphically compares results of input process parameters at various stages and visualize the results of the response parameters for different combinations of inputs. A relatively flat line shows the mean of all the responses in the data table of the experiments. This indicates that the points near to the mean line has less effect

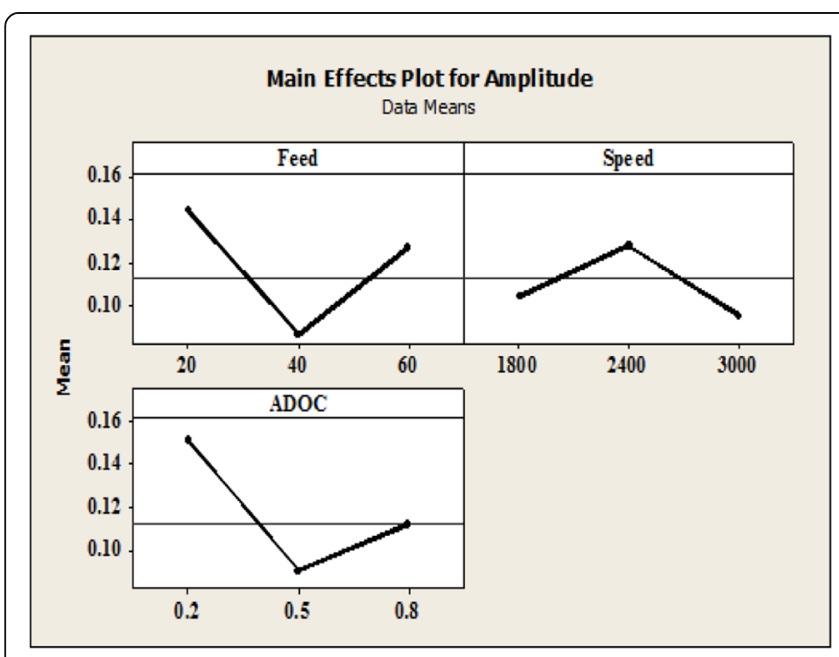

(a)

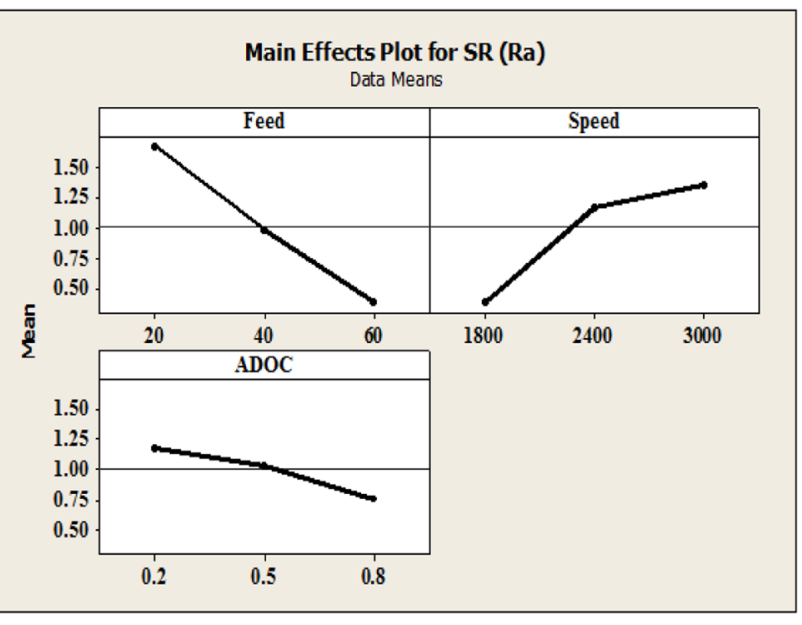

(b)

Fig. 5 Main effects plot for the response. a Amplitude of vibration. $\mathbf{b}$ surface roughness 


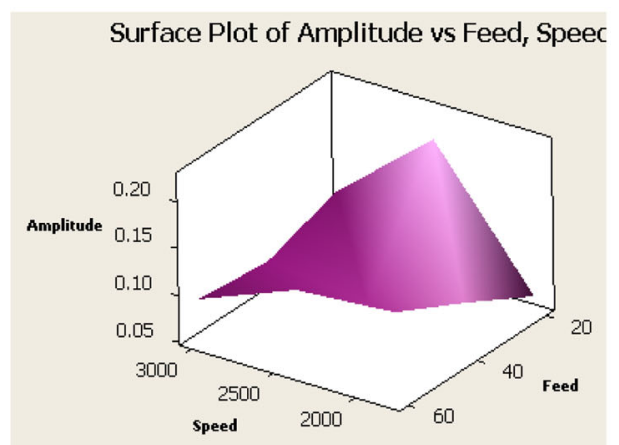

(a)

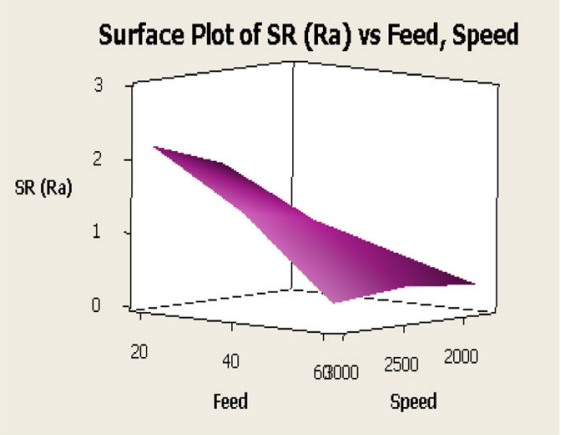

(b)

Fig. 6 Interaction plots of response with feed and speed. a Amplitude. b surface rourghness

on the response parameters whereas the points that are lie on the above and below the mean line are having greater effect on the outputs. The effects are the differences between the means and the reference line. For the case of amplitude of vibration (A), the optimum process parameters were feed of $20 \mathrm{~mm} / \mathrm{min}$, speed of $2400 \mathrm{rpm}$ and the axial depth of cut $0.2 \mathrm{~mm}$ as shown in Fig. 5(a). Similarly, in surface roughness the parameters are feed $20 \mathrm{~mm} / \mathrm{min}$, speed of $3000 \mathrm{rpm}$ and axial depth of cut of $0.2 \mathrm{~mm}$.

\section{Interaction plots of responses}

The 3-D surface plots are considered as a function of two factors at a time. These response factors at fixed levels provides information of interaction effects with the two input factors, and helps to identify the optimum level for each variable to get the maximum response. Figure 6 shows the surface plots of amplitude and surface roughness with variation in the values of feed and speed. It is observed that as the spindle speed increases from 2000 to $2500 \mathrm{rpm}$ the amplitude of the tool vibration level increases and reduces further. In the surface roughness plots, it is observed that as the feed rate increases the roughness value increases and there less significance due to spindle speeds. The optimal surface roughness is obtained with the combination of high spindle speed and with low feed rate values.

Similarly the surface plots are obtained for the responses versus the axial depth of cut (ADOC) and feed rate as shown in Fig. 7. It is observed that for the feed rate of $40 \mathrm{~mm} / \mathrm{min}$ and a depth of cut of $0.4 \mathrm{~mm}$, the amplitude of tool vibration levels are low. Thereafter, as the feed and depth of cut increases the vibration levels also raises significantly. The surface roughness value increases at a depth of cut $0.2 \mathrm{~mm}$ and a feed rate of $20 \mathrm{~mm} / \mathrm{min}$. Further, as the feed rate and depth of cut increases, there is a downfall in the surface roughness values.

Further the resposne plots are obtained for the depth of cut and speed as shown in Fig. 8. At a low speeds and depth of cuts the amplitude of vibration levles rises. Similary the surface roughness value is high at $2500 \mathrm{rpm}$ at a feed rate of $0.2 \mathrm{~mm}$ depth of cut. As the speed increases there is low surface roughness values at the depth of $0.2 \mathrm{~mm}$. This signifies that high speeds and low depths of cut are preferable to obtain the good surface finish.

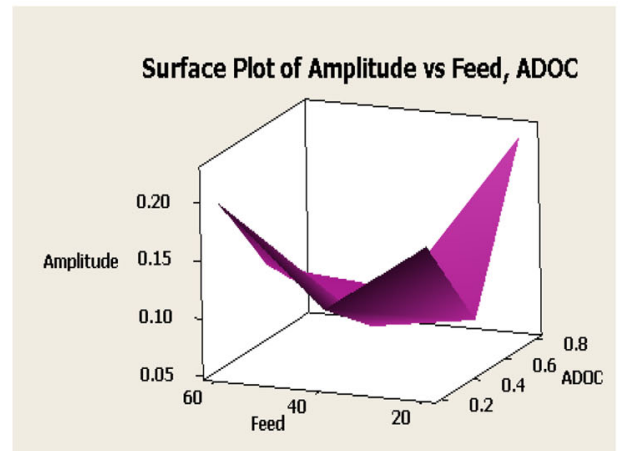

(a)

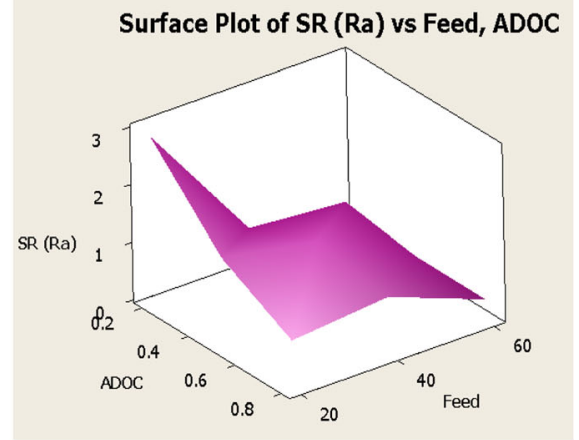

(b)

Fig. 7 Interaction plots of response with feed and depth of cut. a Amplitude. $\mathbf{b}$ surface rourghness 


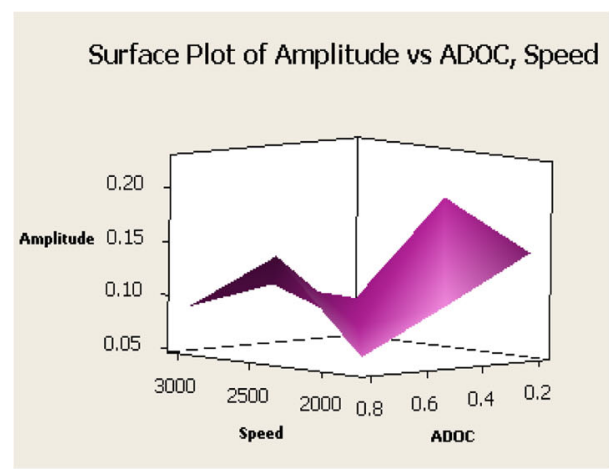

(a)

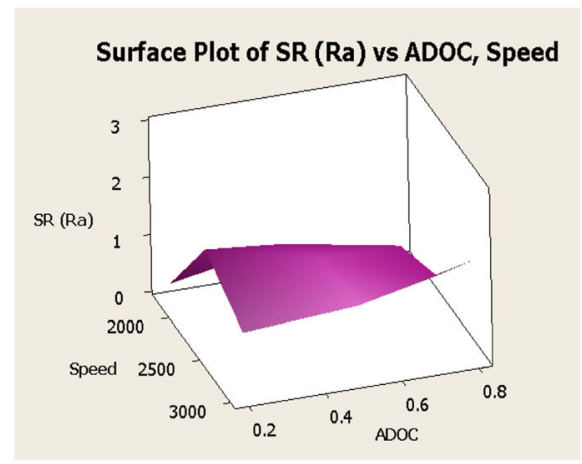

(b)

Fig. 8 Interaction plots of response with depth of cut and speed. a Amplitude. b surface rourghness

Training with radial basis function (RBF) neural netwoks Recently, the radial basis neural network, has been drawing attention due to its simple network structure which reduces the lengthy mathematical calculations and the good generalization capability as compared to the other popular neural network techniques. In general, the RBF networks consists of three layers such as (a) the input layer (b) the hidden layer and (c) the output layer. The hidden layer neurons are activated by the radial basis function. The model data shown in the Table 2 is trained using a radial basis neural network model trained with various input vectors so as to reduce the error between the plant data and neural network outputs. In most of these networks, the neuron in the hidden layer generally possesses the transfer function which is radially symmetrically in nature as shown in the Fig. 9.

In modelling the neurons of the hidden layer of the RBF network, to be radially symmetric it must contain the following three elements.

(i) Centre: It is the input domain vector, generally saved in the output layer weights in the hidden layer neuron. (ii) Measurements of distance: It is considered as the distance between the hidden node centre (c) and the input parameter vector $(\mathrm{x})$ called the Euclidian distance of measure and it is given as $\left\|x(t)-c_{j(t)}\right\|$.

(iii)Transfer function: It describes the functional mapping of the central nodal vector distance and the output of the neuron. When the distance of measure between the two vectors are small, then preferably transfer such as Gaussian function is used which mainly amplifies the values of the output vector. The Gaussian function parameter width for the $\mathrm{k}^{\text {th }}$ unit of the hidden neuron vector is evaluated by the following expression:

$$
\sigma_{k}=\sqrt{\frac{1}{P} \sum_{P=1}^{P}\left\|c_{k}-c_{k p}\right\|^{2}}
$$

Where the $P$ is the value determined heuristically for the method of the closest neighbors; given a cluster center $c_{k}$, let $k_{1}, k_{2}, \ldots . ., k_{P}$ be the indices of the P nearest neighboring cluster centers.

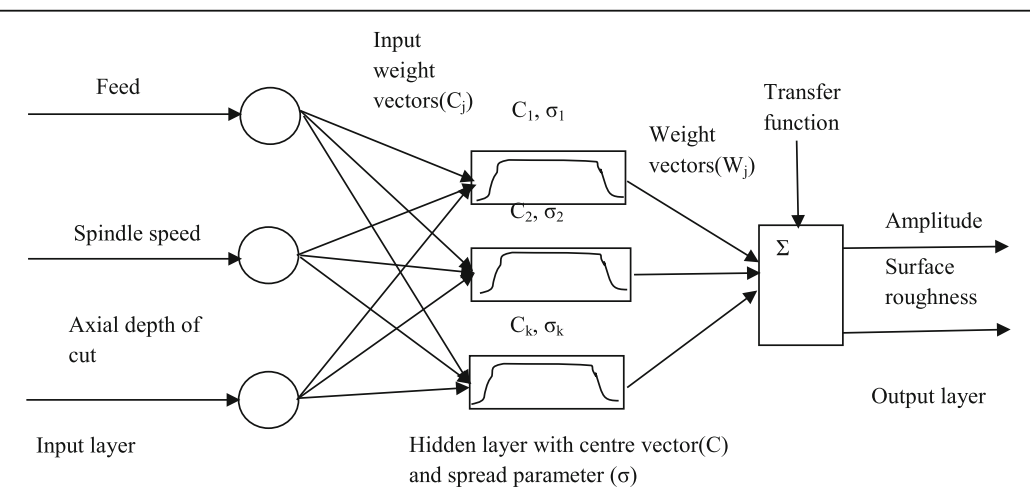

Fig. 9 Schematic diagram of RBFN architecture 


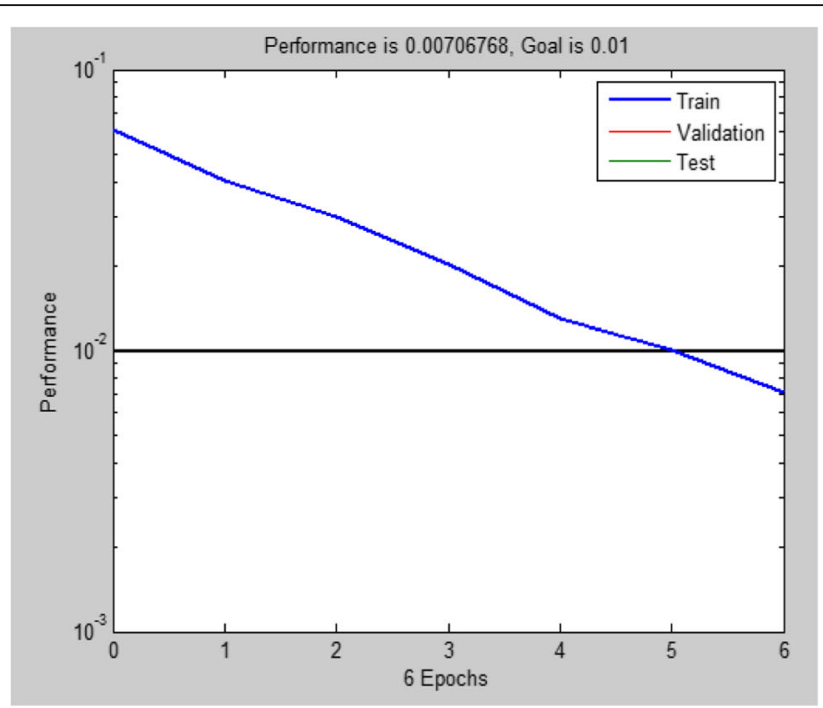

(a)central vector of 6

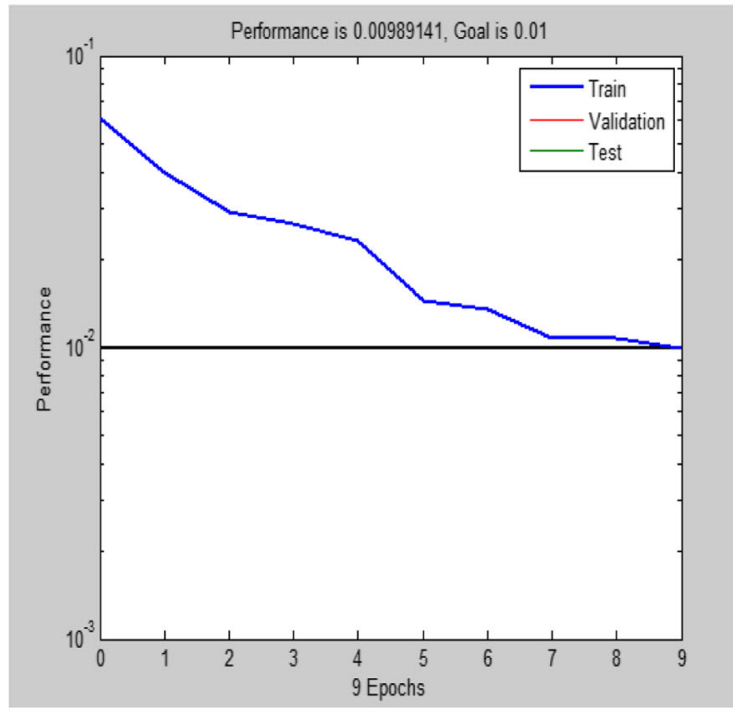

(c) central vector of 9

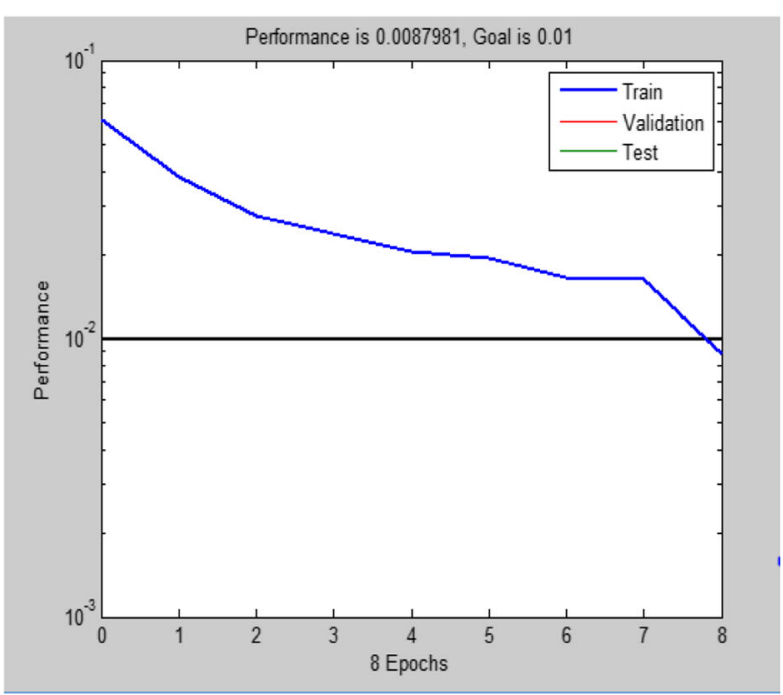

(b)central vector of 7

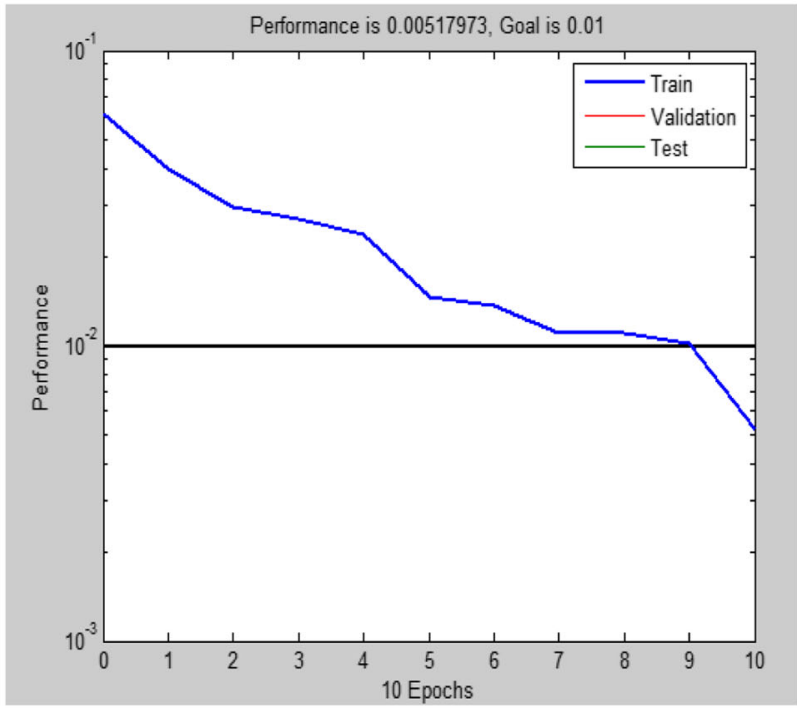

(d) central vectors of 10

Fig. 10 Trained neural network Skelton for different input vectors. a central vector of 6. b central vector of 7. c central vector of 9 . $\mathbf{d}$ central vectors of 10

Table 3 Output results of the trained neural network model

\begin{tabular}{|c|c|c|c|c|c|c|c|c|c|}
\hline \multirow[t]{3}{*}{ Case } & \multicolumn{3}{|l|}{ Inputs } & \multicolumn{6}{|l|}{ Outputs } \\
\hline & \multirow{2}{*}{$\begin{array}{l}\text { fin } \mathrm{mm} / \\
\min \end{array}$} & \multirow{2}{*}{$\begin{array}{l}\mathrm{N} \text { in } \\
\mathrm{rpm}\end{array}$} & \multirow{2}{*}{$\begin{array}{l}\mathrm{b} \text { in } \\
\mathrm{mm}\end{array}$} & \multicolumn{3}{|c|}{ Amplitude of vibration(A) in mv } & \multicolumn{3}{|c|}{ Surface roughness $\left(R_{a}\right)$ in $\mu \mathrm{m}$} \\
\hline & & & & Initial Value & RBF Value & $\%$ error & Initial Value & RBF Value & $\%$ error \\
\hline 1 & 20 & 1800 & 0.5 & 0.064 & 0.06479 & 0.005 & 0.8 & 0.824 & 0.0002 \\
\hline 2 & 20 & 3000 & 0.5 & 0.1128 & 0.1228 & 0.001 & 2.2 & 1.45 & 0.07 \\
\hline 3 & 40 & 1800 & 0.2 & 0.1462 & 0.1189 & 0.002 & 0.2 & 0.49 & 0.002 \\
\hline 4 & 40 & 3000 & 0.8 & 0.0896 & 0.0912 & 0.0001 & 1.73 & 1.56 & 0.0017 \\
\hline 5 & 40 & 2400 & 0.5 & 0.0752 & 0.074 & 0.0001 & 1.2 & 0.95 & 0.002 \\
\hline
\end{tabular}


In the present work, feed, spindle speed and axial depth of cut are given as inputs and normalized values of amplitude of tool vibration levels and surface roughness are provided as target parameters. The RBF model is trained such that it gives the values of vibration levels and surface roughness values for any unknown input data. From various trails of different input vectors, the best possible RBF skeleton is chosen. Figure 10 shows the convergence of training trend with such an input training vectors.

The output results of the test data with the input data are obtained after training. The neural network trained data and experimental output data are compared and depicted in Table 3.

Using the RBFN, the percentage of error is less than $1 \%$ for the central vector of 9 . It is confirmed from these above simulations, that the level of error are acceptable. The modeled algorithms in this work could be implemented and it can be further used efficiently in the estimation of correct process parameter studies.

\section{Optimization using multi-objective GA}

In present work, the above process is simulated with a population size of 60 , selection type is tournament, pareto front population fraction, crossover and mutation probability are selected to be $0.35,1$ and 0.001 , respectively. MATLAB GA toolbox is used in this work. Figure 11 represents the pareto optimal solution for the two objective functions simultaneouly. It is observed that the optimal minimum functional value obtained from the plot as the amplitude of vibrations as $0.251 \mathrm{mv}$ and surface roughness as $2.615 \mu \mathrm{m}$.

A pareto-optimal set of 18 solutions is obtained as shown in Table 4. Moreover, all the solutions in the Pareto-optimal set are almost close to each other but run 6 the values of amplitude and roughness were nearly minimum. The optimal cutting process parameter set is

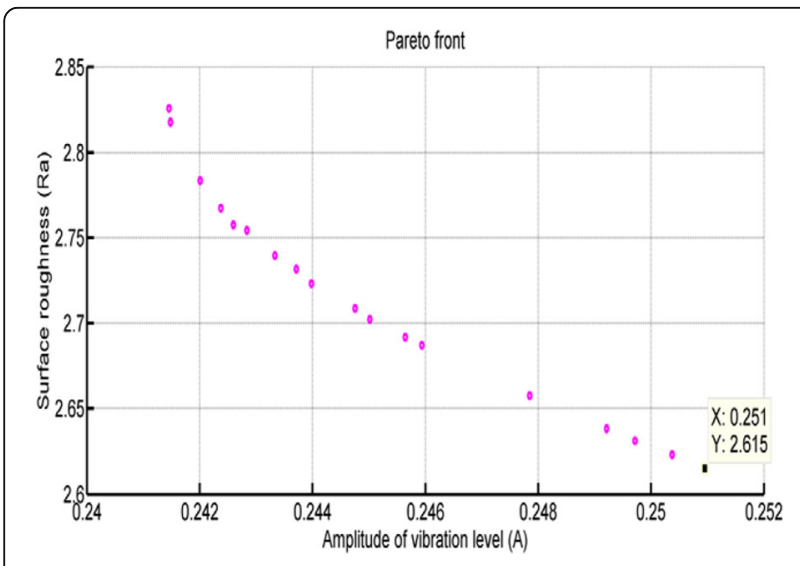

Fig. 11 Pareto optimal plot for the response parameters
Table 4 Pareto optimal solutions obtained from multi-objective GA

\begin{tabular}{lllccc}
\hline $\begin{array}{l}\text { Sl. } \\
\text { No }\end{array}$ & $\begin{array}{l}\text { Speed } \\
(\mathrm{Rpm})\end{array}$ & $\begin{array}{l}\text { Feed } \\
(\mathrm{mm} / \mathrm{min})\end{array}$ & $\begin{array}{l}\text { Axial depth } \\
\text { of cut (mm) }\end{array}$ & $\begin{array}{l}\text { Amplitude of } \\
\text { vibration level } \\
(\mathrm{mv})\end{array}$ & $\begin{array}{l}\text { Surface } \\
\text { roughness } \\
(\text { Ra } \mu \mathrm{m})\end{array}$ \\
\hline 1 & 1800.730 & 41.525 & 0.658 & 0.241 & 2.825 \\
2 & 1800.994 & 41.751 & 0.689 & 0.242 & 2.783 \\
3 & 1800.902 & 41.623 & 0.700 & 0.242 & 2.767 \\
4 & 1801.054 & 41.675 & 0.709 & 0.242 & 2.754 \\
5 & 1801.026 & 41.822 & 0.795 & 0.250 & 2.622 \\
6 & 1800.954 & 41.826 & 0.799 & 0.251 & 2.615 \\
7 & 1800.954 & 41.828 & 0.730 & 0.243 & 2.723 \\
8 & 1800.819 & 41.813 & 0.706 & 0.242 & 2.757 \\
9 & 1801.005 & 41.818 & 0.790 & 0.249 & 2.631 \\
10 & 1801.089 & 41.808 & 0.754 & 0.245 & 2.687 \\
11 & 1800.974 & 41.628 & 0.750 & 0.246 & 2.691 \\
12 & 1801.107 & 41.782 & 0.773 & 0.247 & 2.657 \\
13 & 1801.036 & 41.711 & 0.785 & 0.249 & 2.638 \\
14 & 1800.735 & 41.553 & 0.664 & 0.241 & 2.817 \\
15 & 1800.950 & 41.629 & 0.719 & 0.243 & 2.739 \\
16 & 1800.980 & 41.578 & 0.739 & 0.244 & 2.708 \\
17 & 1800.962 & 41.792 & 0.744 & 0.245 & 2.702 \\
18 & 1801.063 & 41.633 & 0.725 & 0.243 & 2.731 \\
\hline & & & & & \\
\hline
\end{tabular}

obtained as speed of $1800.954 \mathrm{rpm}$, feed as $41.826 \mathrm{~mm} /$ min and axial depth of cut as $0.799 \mathrm{~mm}$ respectively.

Further confirmation tests are conducted using the trained radial basis neural network model and by the experiments as shown in Table 5. Optimal input set determined from the multi-objective genetic algorithm is used in the simulated neural network model. It is observed that the functional values are close to each other with an error of $0.7 \%$. These optimal combinations of machining parameters which is shown in table, with respect to the reference response parameters, satisfy the real requirement milling operations for the proper machining of Al-6061 alloy.

\section{Conclusions}

This work proposed a multi-objective solution of the cutting process parameters for the minimization of amplitude of vibration levels and surface roughness. Experiments were planned using the response surface methodology with the Box-Behnken design in three levels for the machining of $\mathrm{Al} 6061$ alloy. Based on the above numerical simulations and experimental studies the following conclusions were made:

- It is evident that the spindle speed and axial depth of cut are having significant influence on the 
Table 5 Confirmation table of optimal process parameter

\begin{tabular}{|c|c|c|c|c|c|c|c|c|c|c|c|}
\hline \multirow[t]{3}{*}{ S1 No } & \multicolumn{3}{|c|}{ Optimal input set } & \multicolumn{8}{|l|}{ Outputs } \\
\hline & \multirow{2}{*}{$\begin{array}{l}\overline{f \text { in } m m /} \\
\min \end{array}$} & \multirow{2}{*}{$\begin{array}{l}\mathrm{N} \text { in } \\
\mathrm{rpm}\end{array}$} & \multirow{2}{*}{$\begin{array}{l}\mathrm{b} \text { in } \\
\mathrm{mm}\end{array}$} & \multicolumn{4}{|c|}{ Amplitude of vibration (A) in $\mathrm{mv}$} & \multicolumn{4}{|c|}{ Surface roughness $\left(R_{a}\right)$ in $\mu \mathrm{m}$} \\
\hline & & & & GA Value & RBF Value & Experiment & $\%$ error & GA Value & RBF Value & Experiment & $\%$ error \\
\hline 1 & 41.826 & 1800.954 & 0.799 & 0.251 & 0.236 & 0.249 & 0.796 & 2.615 & 2.458 & 2.598 & 0.650 \\
\hline
\end{tabular}

amplitude of vibrations as compared to the surface roughness. However, the interaction effects signify, that low feed rate with high spindle speed minimizes the surface roughness as well as the amplitude tool vibration levels.

- The mathematical model developed in the work gives the good co-relation between the process parameters and the responses. In addition, the Pareto based multi-objective genetic algorithms model can obtain good quality solutions in short time and are suitable for the multi-objective environment due to its population based nature.

- The confirmatory tests are conducted by using both the experiment and trained radial basis neural network model gives an additional validation for the correctness of the process parameter for multiobjective response.

- With the use of the GA based multi-objective optimization developed in this work, it would be possible to obtain the conditions for good surface finish with a lesser amplitude of vibrations.

\section{Acknowledgements}

There are no acknowledgements for this work.

\section{Funding}

Not applicable for the current project.

\section{Authors' contributions}

All authors contributed widely to the work presented in this paper. All the numerical simulations and experimental works are carried out in National institute of Technology Rourkela. The paper has been carefully written to avoid the mistakes at all stages of the manuscript. Finally, the manuscript has been formulated according to journal guidelines and authors approve final manuscript.

\section{Competing interest}

The authors declare that they have no competing interests.

\section{Received: 3 September 2016 Accepted: 17 February 2017}

Published online: 27 February 2017

\section{References}

Arokiadass R, Palaniradja K, Alagumoorthi N (2012) Prediction and optimization of end milling process parameters of cast aluminium based MMC. Trans Nonferrous Met Soc China 22:1568-1574

Briceno JF, Mounayri H, Mukhopadhayay S (2002) Selecting an artificial neural network for efficient modelling and accurate simulation of the milling process. Int J Mach Tool Manu 42:663-674

Brito TG, Paiva AP, Ferreira JR, Gomes JHF, Balestrassi PP (2014) A normal boundary intersection approach to multi response robust optimization of the surface roughness in end milling process with combined arrays. Precis Eng 38:628-638
Das B, Roy S, Rai RN, Saha SC (2016) Application of grey fuzzy logic for the optimization of CNC milling parameters for Al-4.5\%Cu-TiC MMCs with multi-performance characteristics. Engineering Science and Technology, an International Journal 19:857-865

Dikshit MK, Puri AB, Maity A (2014a) Experimental study of cutting forces in ball-end milling of Al2014-T6 using response surface methodology. Procedia Materials Science 6:612-622

Dikshit MK, Puri AB, Maity A, Banerjee AJ (2014b) Analysis of cutting forces and optimization of cutting parameters in high-speed ball-end milling using response surface methodology and genetic algorithm. Procedia Materials Science 5:1623-1632

Hocheng H, Yen YB, Ishihara T, Yen BK (1997) Fundamental turning characteristics of a tribology-favored graphite/aluminum alloy. Composite material [J]. Compos Part A 28:883-890

Karkalos NE, Galanis NI, Markopoulos AP (2016) Surface roughness prediction for the milling of Ti-6Al-4 V ELI alloy with the use of statistical and soft computing techniques. Measurement 90:25-35

Khorasani AM, Gibson I, Goldberg M, Doeven EH, Littlefair G (2016) Investigation on the effect of cutting fluid pressure on surface quality measurement in high speed thread milling of brass alloy (C3600) and aluminium alloy (5083). Measurement 82:55-63

Mounayri H, Kishawy H, Bricenoa J (2005) Optimization of CNC ball end milling: a neural network -based model. J Mater Process Technol 166:50-62

Mounayri H, Briceno JF, Gadallah M (2010) A new artificial neural network approach to modelling ball-end milling. Int J Adv Manuf Technol 47:527-534

Numan Durakbasa M, Anil A, Ali SV, Asli GB (2015) Optimization of end milling parameters and determination of the effects of edge profile for high surface quality of AISI H13 steel by using precise and fast measurements. Measurement 68:92-99

Palanisamy P, Kalidass S (2014) Prediction of surface roughness for AISI 304 steel with solid carbide tools in end milling process using regression and ANN models. Arab J Sci Eng 39:8065-8075

Palanisamy P, Rajendran I, Shanmugasundaram S (2007) Optimization of machining parameters using genetic algorithm and experimental validation for end-milling operations. Int J Adv Manuf Technol 32:644-655

Rajesh Mathivanan N, Mahesh BS, Anup Shetty H (2016) An experimental investigation on the process parameters influencing machining forces during milling of carbon and glass fiber laminates. Measurement 91:39-45

Ratnam C, Arun Vikram K, Ben BS, Murthy BSN (2016) Process monitoring and effects of process parameters on responses in turn-milling operations based on SN ratio and ANOVA. Measurement 94:221-232

Ren J, Zhou J, Zeng J (2016) Analysis and optimization of cutter geometric parameters for surface integrity in milling titanium alloy using a modified grey-Taguchi method. Proc Inst Mech Eng B J Eng Manuf 230:2114-2128

Saffar RJ, Razfar MR (2010) Simulation of end milling operation for predicting cutting forces to minimize tool deflection by Genetic Algorithm. Machining Science and Technology: An International Journal 14:81-101

Sukumar MS, Venkata Ramaiah P, Nagarjuna A (2014) Optimization and prediction of parameters in face milling of Al-6061 using Taguchi and ANN approach. Procedia Engineering 97:365-371

Surinder K, Meenu G, Satsangi PS (2015) Multiple-response optimization of cutting forces in turning of UD-GFRP composite using Distance-Based Pareto Genetic Algorithm approach. Engineering Science and Technology, an International Journal 18:680-695

Venkata Rao R, Pawar PJ (2010) Parameter optimization of a multi-pass milling process using non-traditional optimization algorithms. Appl Soft Comput 10: 445-456

Wang ZG, Rahman M, Wong YS, Sun J (2005) Optimization of multi-pass milling using parallel genetic algorithm and parallel genetic simulated annealing. Int J Mach Tool Manu 45:1726-1734 
Zain AM, Haron H, Sharif S (2011) Integration of simulated annealing and genetic algorithm to estimate optimal solutions for minimising surface roughness in end milling Ti-6AL-4 V. Int J Comput Integr Manuf 24:574-592

Zhang C, Weidong L, Pingyu J, Peihua G (2016) Experimental investigation and multi-objective optimization approach for low-carbon milling operation of aluminum. Proc I Mech E Part C: J Mechanical Engineering Science. doi:10. $1177 / 0954406216640574$

\section{Submit your manuscript to a SpringerOpen ${ }^{\circ}$ journal and benefit from:}

- Convenient online submission

- Rigorous peer review

- Immediate publication on acceptance

- Open access: articles freely available online

- High visibility within the field

- Retaining the copyright to your article

Submit your next manuscript at $>$ springeropen.com 